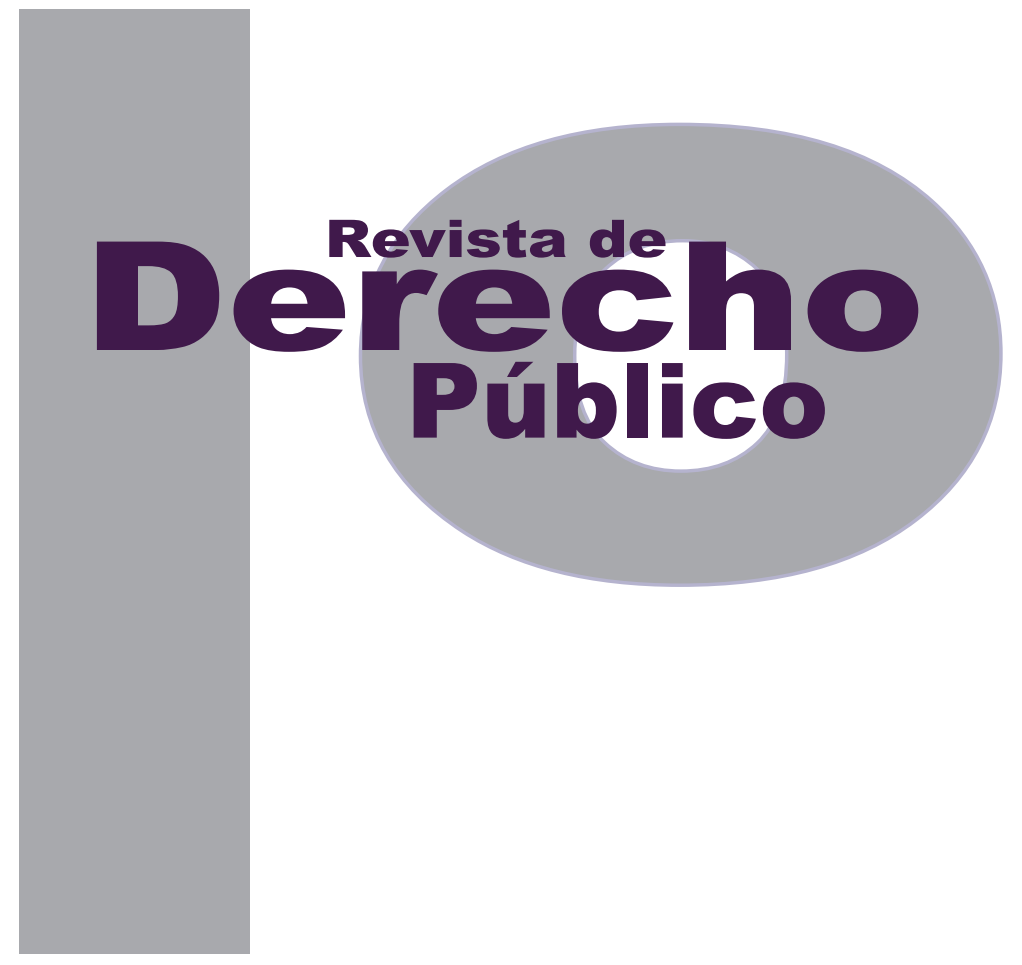

\title{
ANÁLISIS CRÍTICO DE LAS DIRECTIVAS DE INTERPRETACIÓN CONSTITUCIONAL CREADAS POR LA DOGMÁTICA JURÍDICA
}

\author{
ANDRÉS Felipe Zuluaga Jaramillo \\ JEFFERSON BEDOYA ATEHORTÚA
}

Artículo de reflexión

DOI: http://dx.doi.org/10.15425/redepub.33.2014.19

Universidad de los Andes

Facultad de Derecho

Revista de Derecho Público N. ${ }^{\circ} 33$

Julio - Diciembre de 2014. ISSN 1909-7778 


\section{Análisis crítico de las directivas de interpretación constitucional creadas por la dogmática jurídica}

\section{Resumen}

La interpretación de la Constitución ha dado lugar al desarrollo de una serie de estudios que se han ocupado de la noción, del objeto, de las características, de la especificidad de dicha interpretación y de la función del juez constitucional. El presente artículo aborda algunas de esas temáticas, y se centra en el papel de las directivas de interpretación constitucional, recopilando la mayor cantidad de las elaboradas por la doctrina, para luego realizar una crítica a estas. Se describen las directivas tradicionales de interpretación, las cuales se contraponen a los nuevos criterios elaborados por ciertos sectores de la dogmática jurídica, la cual llega inclusive a proponer algunas directivas ya contenidas en otras o que no son relevantes en la práctica, como se pretende evidenciar en este artículo.

Palabras clave: interpretación constitucional, directivas de interpretación, Constitución, discrecionalidad.

\section{Critical analysis of constitutional interpretation directives developed by legal doctrine}

\section{Abstract}

The interpretation of the Constitution has lead to the development of a series of studies devoted to it. It has concerned about the notion, object, characteristics, specificity of constitutional interpretation and the role of constitutional judge. This paper treats this issue, and focuses in the role of constitutional interpretation directives, collecting as much of the doctrine developed, and then criticizing them. Traditional interpretation directives are described; this last ones are opposed to the new criteria that have been developed by certain sectors of the legal doctrine, which goes so far as to propose some directives already contained in other ones or that are not relevant in practice, as is intended to demonstrate in this article.

Keywords: constitutional interpretation, interpretation directives, Constitution, discretion.

\section{Análise crítica das diretivas de interpretação constitucional criadas pela dogmática jurídica} Resumo

A interpretação da Constituição tem dado lugar ao desenvolvimento de uma série de estudos que têm se ocupado da noção, do objeto, das características, da especificidade de dita interpretação e a função do juiz constitucional. 0 presente artigo aborda alguma dessas temáticas, e se centra no papel das diretivas de interpretação constitucional, recopilando a maior quantidade das elaboradas pela doutrina, para depois realizar uma crítica a estas. São descritas as diretivas tradicionais de interpretação, as quais se contrapõem aos novos critérios elaborados por certos setores da dogmática jurídica, a qual chega inclusive a propor algumas diretivas já contidas em outras ou que não são relevantes na prática, como se pretende evidenciar neste artigo.

Palavras-chave: interpretação constitucional, diretivas de interpretação, Constituição, discrição. 


\title{
Análisis crítico de las directivas de interpretación constitucional creadas por la dogmática jurídica*
}

\author{
Andrés Felipe Zuluaga Jaramillo** \\ Jefferson Bedoya Atehortúa***
}

\section{SUMARIO}

Introducción - I. NOCIÓN DE INTERPRETACIÓN CONSTITUCIONAL - II. EL OBJETO DE LA INTERPRETACIÓN CONSTITUCIONAL - III. CARACTERÍSTICAS DE LA INTERPRETACIÓN CONSTITUCIONAL - IV. DIRECTIVAS INTERPRETATIVAS - A. Directivas - 1. Directivas interpretativas generales - 2. Argumentos interpretativos especiales para la Constitución - V. CRÍTICA A LAS DIRECTIVAS DE INTERPRETACIÓN CONSTITUCIONAL CREADAS POR LA DOGMÁTICA JURÍDICA - VI. CONCLUSIONES - Referencias.

* Cómo citar este artículo: Zuluaga Jaramillo, A. F. y Bedoya Atehortúa, J. (Diciembre, 2014). Análisis crítico de las directivas de interpretación constitucional creadas por la dogmática jurídica. Revista de Derecho Público, 33. Universidad de los Andes (Colombia).

** Abogado y magíster en Derecho Procesal de la Universidad de Medellín, docente de tiempo completo y coordinador de la U. O. C de Humanidades de la Universidad de Medellín. Correo: andresfelipezuluaga85@gmail.com

*** Estudiante de Derecho de la Universidad de Medellín. Correo: bedoyajefferson21@gmail.com 
Introducción

Desde épocas remotas el género humano ha buscado patrones de conducta que le permitan vivir en comunidad; estos inicialmente se transmitían por medio de la oralidad y eran aplicados de forma rudimentaria, posteriormente estas disposiciones fueron consagradas en textos y aunque algunas sociedades siguieron conservando en su cultura jurídica la implementación de la costumbre, esto marcó drásticamente la relación texto-intérprete-aplicador del derecho, otorgando a este último la eficacia a la norma, lo cual a la postre pasó a ser ejercido por el aparato estatal, quien lo ha venido haciendo hasta la actualidad.

La norma escrita surge como garantía de la seguridad jurídica, cuya relevancia llega a su cenit durante la Revolución francesa, como respuesta a la arbitrariedad y en nombre de la libertad humana. Del mismo modo, la figura del juez moderno se encargó en principio solo de aplicar las normas jurídicas, principalmente la ley; de esto ha quedado como constante reminiscencia el estribillo tan conocido por los juristas para referirse a sus colegas jueces de entonces: "la boca de la ley", que no de la Constitución, pues esta si bien existía era considerada una declaración abstracta que solo el legislador podía concretar, por lo cual era tema de filósofos y no de juristas.

Se decía entonces que el lenguaje era hermético, por lo cual las leyes del legislador racional, representante de la voluntad popular, contenían todas las respuestas jurídicas necesarias. Por lo anterior, era el parlamento quien protegía la
Constitución, con nefastas consecuencias que para el siglo xx llevaron a la aceptación de la vaguedad del lenguaje en general y del jurídico en particular, como lo expresa López Medina: “Más bien se trata de considerar los problemas y características generales del texto legal que, muy por el contrario de la idea de plenitud hermética del derecho, muestra a cada paso ambigüedad, indeterminación, vaguedad, contradicción e incluso flagrante absurdo" (2008, p. 29), lo cual produjo el reconocimiento, no sin problemas, de la facultad interpretativa y luego además creativa del juez, quien no sería entonces un simple técnico del silogismo judicial, sino el representante del constituyente primario en la tarea de convertir en realidad los preceptos normativos contenidos en la Constitución.

De nuevo surgió la pregunta por la discrecionalidad - entendiendo por tal los "espacios de libertad en los que el operador puede elegir entre una u otra posibilidad" (Ruiz, p. 7) - que los preceptos de la Constitución, caracterizados por su generalidad y vaguedad, otorgaban al juez. La cuestión entonces fue con cuál regla se decide entre el espectro de posibilidades ofrecidas por la Constitución. Los criterios de interpretación, si bien desprovistos de jerarquía y tan variados como las mismas opciones de elección, se constituían en una herramienta para disminuir la discrecionalidad judicial, que no de eliminarla, pues esta es inherente a la actividad judicial. Así pues, las directivas de interpretación permitirían ejercer un control intersubjetivo de las decisiones jurídicas.

El primer autor en referirse a los criterios interpretativos fue Savigny (1979, pp. 13 y 14), 
quien señaló como tales el gramatical, el lógico, el histórico y el sistemático. Mucho se ha escrito desde entonces respecto al tema, la mayoría de los autores han pretendido hacer su aporte al constitucionalismo a partir de la creación de nuevos criterios, llegando inclusive a proponer algunos ya contenidos en otros o no relevantes en la práctica, como se pretende evidenciar en este artículo.

Afirma Guastini que la interpretación constitucional puede ser abordada desde dos perspectivas diametralmente distintas: una prescriptiva o doctrina ideológica de la interpretación constitucional, a partir de la cual se recomienda la utilización de un determinado criterio de interpretación, excluyendo otros posibles; y otra descriptiva, también llamada teoría de la interpretación constitucional, que "consiste precisamente en describir y analizar las técnicas efectivamente utilizadas por jueces y juristas cuando interpretan la Constitución" (2010, p. 52), es este el punto de partida que se acoge en el presente texto a fin de propiciar la discusión sobre las nuevas corrientes de la doctrina constitucional.

\section{NOCIÓN DE INTERPRETACIÓN CONSTITUCIONAL}

El rasgo central para una noción de la interpretación constitucional es la atribución de significado a las disposiciones jurídicas desde el texto constitucional, pues como lo señala Vigo respecto del modelo de Estado Constitucional “la teoría de la interpretación jurídica aparece como una dimensión inescindible y principal de la teoría del Estado y del derecho constitucional" (2004, p. 79). Con base en lo anterior, la interpretación jurídica constitucional realizada por los tribunales constitucionales puede ser definida como aquella actividad que procura determinar el sentido de las disposiciones jurídicas constitucionales, y a partir de allí de los textos normativos de inferior jerarquía o de comportamientos conformes o no con la Constitución, con pretensiones de corrección, teniendo en cuenta además como lo resalta Hesse "que el proceso de concretización debe venir determinado por el objeto de la interpretación -la Constitución-y por el problema en cuestión" (2011, p. 65).

Al expresar comportamientos conformes o no con la Constitución se alude principalmente a los juicios de amparo, en los cuales el tribunal constitucional determina si una acción u omisión concreta, realizada por ciertos sujetos, vulnera o no los derechos humanos. En el caso del Estado colombiano esta interpretación se efectúa por medio de las sentencias de los jueces que ejercen funciones constitucionales.

Con respecto a la pretensión de corrección, Alexy ha afirmado que "Los discursos son conjuntos de acciones interconectadas en los que se comprueba la verdad o corrección de las proposiciones" (2007, p. 177). De este modo, al contener las sentencias de los tribunales decisiones respaldadas por argumentos, estos deben tratar de mostrar que las interpretaciones son correctas con base en la Constitución Política. Esta pretensión de corrección tiene importancia fundamental en los Estados constitucionales democráti- 
cos, en la medida que desde los discursos contenidos en las sentencias de constitucionalidad o de amparo se determinan los límites válidos de las interpretaciones jurídicas realizadas por los demás operadores jurídicos.

Así pues, la existencia de un catálogo de derechos, la decisión por un órgano colegiado y la polémica que han generado ciertas sentencias de los tribunales constitucionales son aspectos que contribuyen a que la pretensión de corrección de la interpretación constitucional sea algo complejo, pero a lo cual no se puede renunciar, pues sobre la pretensión de corrección descansa, por así decirlo, la legitimidad del órgano constitucional ante la sociedad. En consecuencia, no puede sostenerse que exista una corrección absoluta, pero sí debe exigirse una corrección relativa que "pueda tornarse traslúcida, convincente y, al menos hasta cierto punto, previsible" (Quiroga, 2005, p. 962). Y a ello contribuye la interpretación constitucional, no en vano se ha expresado que la función más importante de esta es "postular respuestas constitucionalmente correctas al término de un procedimiento racional y controlable y fundamentar dichas soluciones de manera igualmente racional y controlable para así garantizar la certeza y seguridad jurídica" (Arango, 1993, p. 35).

\section{EL OBJETO DE LA INTERPRETACIÓN CONSTITUCIONAL}

El objeto de la interpretación constitucional es el texto constitucional, y en el Estado colombiano se puede agregar como objeto las disposiciones jurídicas que conforman el bloque de constitucionalidad. De ahí que los tribunales constitucionales deben interpretar los textos con rango constitucional, y desde allí tomar las respectivas decisiones ya sea en sede de control de constitucionalidad o en el contexto de los juicios de amparo. La importancia de resaltar el objeto de la interpretación constitucional se fundamenta en que "la constitución crea y determina el sistema jurídico, de su carácter supremo se sigue que es el sistema de significaciones jurídicas del cual se derivan los significados de las demás normas del sistema" (Huerta, 2008, p. 313).

En ese sentido, si los tribunales constitucionales son los órganos de cierre respecto de la Constitución, los significados de las disposiciones del resto del ordenamiento jurídico dependen en gran medida de lo que ha interpretado el tribunal constitucional. Por ello "el papel de las constituciones en los ordenamientos jurídicos es el de la fijación del marco argumentativo y justificatorio de las normas y las decisiones, pero no en el sentido de proporcionar soluciones sino más bien en el de fijar los límites de la discusión" (Asís, 2008, p. 217).

Por ello, el objeto de la interpretación constitucional es el rasgo común de la interpretación jurídica de los estados constitucionales demo- 
cráticos, el cual no se puede perder de vista so pena de vulnerar el texto constitucional que, como se sabe, irradia el ordenamiento jurídico; dicho de otro modo, es el centro hacia el cual convergen las demás disposiciones de dicho ordenamiento. De esta manera se itera que la interpretación constitucional tiene "por objeto lograr que la Constitución formal refleje la Constitución material, es decir, darle contenido y vida a la Constitución escrita" (Rivera, 2005, p. 986). En otras palabras, el objeto de la interpretación constitucional es el texto constitucional, frente al cual se propone el intérprete lograr una adecuada materialización de sus disposiciones, que permita su vocación de permanencia en el tiempo y, por ende, evite múltiples reformas. No obstante, es preciso tener cuidado con la mutación constitucional.

\section{CARACTERÍSTICAS DE LA INTERPRETACIÓN CONSTITUCIONAL}

Por la especificidad del objeto de la interpretación constitucional, esta posee unas características particulares que la distinguen de la interpretación jurídica realizada con base en otro tipo de textos como los legales. Algunas peculiaridades son:

(i) El lenguaje utilizado por las constituciones: en ellas se encuentran "términos valorativos, cuasidescriptivos y descriptivos" (Wróblewski, 1988, p. 106). Con respecto a los términos cuasidescriptivos es necesario precisar que tienen una apariencia descriptiva, pero en el fondo son valorativos. La consecuencia de la alta presencia de términos valorativos y cuasidescriptivos en las constituciones es la posibilidad de acudir a criterios políticos para interpretar con base en los valores. Verbigracia: al interpretar el término vida, el significado que se le determinará será diferente según lo realice un defensor de los valores del catolicismo o un ateo liberal.

(ii) Los resultados de la interpretación constitucional: con este tipo de interpretación se aumentan o disminuyen los significados atribuibles de manera válida a las diversas disposiciones jurídicas. Por ello no es gratuito que producto de la interpretación constitucional se declaren inexequibilidades, o constitucionalidades condicionadas.

(iii) La vaguedad de las disposiciones constitucionales: algunas de las palabras usadas por las constituciones poseen un alto grado de indeterminación, esto es, no existe claridad en cuáles son las características o el campo de aplicación de los términos, lo cual trae como consecuencia "la dificultad de establecer mecanismos que garanticen el respeto a un supuesto significado mínimo" (Asís, 2008, p. 222).

Con base en la indeterminación de las disposiciones contenidas en la Constitución se ha afirmado que estas funcionan más bien como motivos para tomar la decisión, puesto que "no brindan una determinación clara del supuesto de hecho y sus consecuencias jurídicas precisas -como es el caso de las 
reglas, o normas en sentido estricto- sino solo motivos que no obligan a una decisión más o menos única" (Toller, 2005, p. 1256).

(iv) Se realiza en concreto: la interpretación constitucional adquiere pleno sentido cuando se efectúa analizando casos concretos como en los juicios de amparo o en los de control de constitucionalidad, porque a partir de allí se establece qué conductas o disposiciones son contrarias a la Constitución. Realizar interpretaciones constitucionales en abstracto puede conllevar la realización de discursos constitucionales desarraigados de la realidad y altamente valorativos. Por ello se ha expresado que "la interpretación ha de hacerse desde la situación concreta hacia la norma constitucional y no en sentido inverso... donde la norma es el marco de valoración ascendente" (Quiroga, 2005, p. 952).

(v) La no existencia de un único método: para interpretar constitucionalmente no existe una única manera de hacer las interpretaciones, por ello se ha rechazado "toda pretensión de pureza metodológica que imponga al intérprete el uso exclusivo y absoluto de un método determinado a la manera de las fórmulas matemáticas o las recetas medicinales" (Linares, 2005, p. 766).

(vi) Es una interpretación de límites, en el sentido de establecer unos mojones a las competencias de los diversos órganos del Estado. Por ello una actuación que sobrepase los límites establecidos por el tribunal constitu- cional tendrá problemas respecto de su validez. Por tanto no es gratuita la afirmación "La Constitución es exclusivamente límite, ya que su función no es la de crear derecho, sino la de impedir que se cree derecho anticonstitucional" (Pérez, J., 2005, p. 898).

El estar relacionada con la validez de los textos normativos llevó a proponer, entonces, la idea de las cadenas de validez, las cuales dependen del documento constitucional. Así “Los materiales jurídicos (leyes, testamentos, tratados, Constitución, embargos) no son independientes unos de otros, por el contrario se relacionan en "cadenas de validez' donde la función constitucional explica su alcance y significado" (Tamayo, 2005, p. 1171).

(vii) No busca la única respuesta correcta: se ha sostenido que por medio de la interpretación no se pretende llegar a una única solución para los casos concretos, más bien hay respuestas que son más conformes con la Carta constitucional que otras. De este modo, "la misión de la justicia constitucional no es tanto la de precisar la 'mejor' o la 'única' respuesta posible, sino más bien la de indicar qué interpretaciones resultan intolerables" (Prieto, 2005, p. 921).

(viii) La interpretación constitucional tiene un marcado carácter político: ${ }^{1}$ se afirma que

Canosa expresa que lo particular de esta actividad es operar como "Un derecho regulador de lo político" (2005, p. 244).

También se ha dicho que "Los problemas constitucionales son problemas de poder, es decir, políticos" (Carpizo y Fix-Zamudio, 2005, p. 432). 
“El derecho constitucional es, pues, derecho político que, sin embargo, hay que interpretar jurídicamente" (Würtenberger, 2005, p. 1371). Esta cita trata de paliar un poco el carácter político de la interpretación, y a su vez proponer que lo mejor es que esta sea lo más jurídica posible para así limitar el poder de los tribunales constitucionales.

(ix) Es pluralista: conforme a esta característica "las Constituciones se presentan como órdenes abiertas en donde no hay valores absolutos. El pluralismo axiológico conduce así a Constituciones abiertas donde lo único absoluto acaso sea su apertura constante y necesaria" (Canosa, 2005, p. 239). Así, por ser la Constitución un texto que trata de unificar una nación en la cual sus habitantes tienen posturas ideológicas diferentes, consagrar la jerarquía de algún valor puede generar la exclusión de algún sector de la población, por ello la interpretación constitucional debe permanecer abierta para dar acogida a todos los habitantes.

(x) Creación de normas subconstitucionales: una de las características más peculiares de la interpretación constitucional es que gracias a esta surgen normas subconstitucionales, o reglas adscriptas, por ello "la carta fundamental se ha integrado de manera paulatina por un acervo muy numeroso de lo que la doctrina ha calificado como normas subconstitucionales, es decir, las creadas por las sentencias de los jueces constitucionales de última instancia" (FixZamudio, 2005, p. 562).

\section{DIRECTIVAS INTERPRETATIVAS}

Se entiende por directivas interpretativas aqueIlas pautas a las cuales puede acudir el juez constitucional al momento de determinar y justificar el significado atribuido a las disposiciones normativas constitucionales y legales.

Estas son importantes en la medida que "un faIlo sin fundamentación es el paradigma de una sentencia arbitraria por muy conforme a Derecho que el fallo sea" (Aguiló, 1997, p. 75). Por tanto, la utilización de directivas interpretativas en las decisiones judiciales es una posible garantía de no arbitrariedad de la decisión judicial.

Por añadidura, “la motivación de la sentencia es el canal de legitimación de la decisión, y en este sentido es posible afirmar que el método jurídico posee relevancia constitucional" (Asís, 1995, p. 110). Qué mejor manera de atribuir significado y motivar las providencias que utilizando los consabidos cánones de interpretación jurídica, que son producto de la metodología jurídica.

Igualmente se ha expresado: "lo que hace bueno un fallo es la calidad de los argumentos con que se motive cada uno de los pasos que llevan a él" (García, p. 51). Ahora bien, la calidad de los argumentos viene decantada por la doctrina y la jurisprudencia, las cuales han erigido y aportado una serie de argumentos que pueden ser utilizados en las providencias judiciales.

Es de anotar que estos cánones interpretativos pueden ser generales o sectorizados. Los generales pueden ser utilizados frente a cualquier 
disposición jurídica y los especiales solo sirven en determinadas áreas del derecho, como "la regla del favor laboratoris en derecho laboral, la del favor minoris en derecho de menores, la del favor libertatis en derecho penal" (García, p. 51).

Así, algún sector de la doctrina ha generado directivas especiales para la interpretación de la Constitución, por considerar que "Ios tradicionales criterios de interpretación jurídica (gramatical, histórico, sistemático y teleológico) resultan insuficientes para interpretar los derechos fundamentales en el Estado constitucional" (Pérez, P., 2005, p. 904). Se señala esta insuficiencia por las particularidades que tienen las normas que consagran derechos fundamentales; un claro ejemplo de estos argumentos especiales es el principio pro personae. En similar sentido se pronuncia Vega, quien expresa que "Al criticar los métodos tradicionales de interpretación, se tiene en mente el objetivo de demostrar que los mismos en ocasiones son insuficientes para interpretar la Constitución" (2005, p. 1312). ${ }^{2}$

\section{A. Directivas}

La presentación de las directivas que se hace en este aparte pretende mostrar la mayor cantidad de argumentos interpretativos que pueden ser utilizados al momento de justificar una decisión.

En torno a la utilización del concepto de directiva en la doctrina constitucional es pertinente señalar que existe una cierta confusión de esta

2 En similar sentido: "Los criterios de interpretación de la ley no pueden trasladarse exactamente a la interpretación de la Constitución" (Aragón, 2005, p. 44). con palabras tales como: métodos, principios o criterios de interpretación, lo que ha llevado en ocasiones al uso indistinto de estos y puede ser contraproducente para la dogmática jurídica, que se ha caracterizado especialmente a partir de Kelsen por propender la decantación del lenguaje jurídico. ${ }^{3}$

\section{Directivas interpretativas generales}

Lingüística: como se colige, esta directiva implica acudir al lenguaje para interpretar las diversas disposiciones. Esta directiva a su vez diferencia entre dos contenidos:

Semántico: el cual remite al significado de las palabras y es el punto de partida de cualquier argumentación. El Código civil consagra de manera muy clara este tipo de argumento en dos de sus artículos, ${ }^{4}$ distinguiendo entre el significado legal, el técnico y el "natural". 5

Sintáctico: encaminado "a la evaluación de la estructura gramatical o formal del enunciado normativo" (Huerta, 2008, p. 307).

3 Ejemplos de este fenómeno en: Hesse (2011, pp. 61, 67 y 69; Monroy (2002, p. 85).

$4 \quad$ Artículo 28.- Las palabras de la ley se entenderán en su sentido natural y obvio, según el uso general de las mismas palabras; pero cuando el legislador las haya definido expresamente para ciertas materias, se les dará en estas su significado legal.

Artículo 29.- Las palabras técnicas de toda ciencia o arte se tomarán en el sentido que les den los que profesan la misma ciencia o arte; a menos que aparezca claramente que se han tomado en sentido diverso.

5 Se utiliza la expresión natural para respetar la denominación dada por el Código civil, sin embargo se aclara que para el autor las palabras no tienen significado natural, pues ello sería acogerse a definiciones esencialistas. 
La directiva en comento es el punto de partida de cualquier interpretación jurídica, sea constitucional o no. Sin embargo, por las particularidades de las normas constitucionales este canon no tiene la suficiente entidad como para fundar por sí mismo una decisión judicial, de ahí que "el respeto al texto, que es siempre fundamental en la interpretación jurídica, se revela apenas como un comienzo (por demás insuficiente) de la interpretación de la Constitución" (López, 2005, p. 790). En similar sentido se ha expresado que al momento de hacer operativo el derecho, el carácter lingüístico “actúa siempre como marco necesario de referencia de la actividad interpretativa" (Rivera, 2005, p. 987).

Sistemática: como se puede inferir, esta directiva parte del presupuesto de que el ordenamiento jurídico es un sistema unitario, coherente y pleno. En virtud de estas características se pueden extraer criterios para la interpretación de las disposiciones normativas, y especialmente para la interpretación del texto constitucional que es el encargado de garantizar la unidad del ordenamiento jurídico. Además, todas las normas por mandato constitucional deben ser coherentes con la Constitución, ${ }^{6}$ y por último las lagunas solo pueden ser llenadas de manera que no vulneren el texto constitucional. De este modo se encuentran:

Argumentos que aseguran la consistencia o la coherencia: estos "hacen posible una interpretación que impide o resuelve los conflictos entre

Artículo 4.- La Constitución es norma de normas. En todo caso de incompatibilidad entre la Constitución y la ley u otra norma jurídica, se aplicarán las disposiciones constitucionales. normas" (Huerta, 2009, p. 258). Así, por medio de este argumento se pretenden derrotar las antinomias que se puedan presentar en el ordenamiento jurídico.

Argumentos contextuales: por medio de los cuales se pretende que la norma jurídica sea interpretada según la ubicación en que esta se encuentra conforme al ordenamiento jurídico. ${ }^{7}$

Argumentos de economía: estos buscan que no existan disposiciones normativas repetidas en el ordenamiento jurídico, "de esa manera si hay dos normas que dicen lo mismo puede procurarse establecer que se trata de hipótesis o respuestas diferentes" (Vigo, 2004, p. 227).

Teleológica: como la palabra lo dice, por medio de esta directiva se pretende indagar cuál es el objetivo o propósito que persigue la disposición jurídica. De ahí que se pueda expresar que se "busca interpretar la norma a partir de su finalidad indagando los fines que están ocultos en la norma para darle sentido" (Olano, 2005, p. 44). Para algunos autores ${ }^{8}$ esta es la directiva más importante en el contexto de la interpretación constitucional, por ello se ha sostenido que "debe siempre prevalecer el contenido teleológico o finalista de la Constitución, que si es instrumento de gobierno, también y principalmente es

7 Código Civil, artículo 30.- El contexto de la ley servirá para ilustrar el sentido de cada una de sus partes, de manera que haya entre todas ellas la debida correspondencia y armonía.

Los pasajes oscuros de una ley pueden ser ilustrados por medio de otras leyes, particularmente si versan sobre el mismo asunto.

8 En este mismo sentido "Utilícese el método gramatical, histórico y lógico-sistemático, pero siempre en razón del fin extraído de la Norma Fundamental" (Zaldívar, 2005, p. 1405). 
restricción de poderes en amparo de la libertad individual" (Linares, 2005, p. 767).

Se ha precisado respecto de la directiva en estudio que "la interpretación teleológica de las normas constitucionales exige que, junto a la finalidad de la norma, se busque el telos de la propia Constitución, que no es otro que la creación y mantenimiento de un orden abierto a todas las posibilidades respetuosas de la dignidad humana y de la libertad, y que no impida la alternativa política" (Torres del Moral, 2005, p. 1291).

De este modo, cualquier interpretación jurídica realizada desde la Constitución Política de un Estado constitucional democrático debe tener en cuenta los fines perseguidos por esta, y en especial su marcada orientación a proteger derechos humanos tan caros como la dignidad y la libertad.

Sin embargo, esta no es una cuestión libre de tensiones. En este sentido se ha afirmado desde otras perspectivas "La 'interpretación teleológica' es prácticamente una carta blanca, pues con la regla de que hay que plantearse el sentido de un precepto no se avanza nada respecto de la pregunta fundamental, la de cómo descubrir dicho sentido" (Hesse, 2011, p. 61).

Histórica: esta directiva supone expresar cuál fue el contexto temporal y especial de expedición de la norma, para así comprender a cabalidad la disposición jurídica, y desde este contexto determinar su sentido. Por ello, "salvo que se deduzca otra cosa, a los enunciados normativos se les debe atribuir el significado que tradicio- nalmente se les venía otorgando" (Betegón, 1997, p. 365). En el mismo sentido el artículo 27 del Código civil consagra que para interpretar se puede acudir a "la historia fidedigna de su establecimiento".

Sociológica: es verdad de Perogrullo que la sociedad cambia más rápido que el derecho, lo cual puede ocasionar la obsolescencia de las disposiciones jurídicas. Para evitar este problema "se ordena que los enunciados jurídicos se interpreten teniendo en cuenta, no la realidad que contempló el autor de la norma, sino la realidad del tiempo en que ha de ser aplicada" (Betegón, 1997, p. 365). Con base en esta directiva se puede sostener que un texto constitucional debe ser lo menos modificado posible, ya que sus disposiciones pueden ser interpretadas por el tribunal constitucional de manera sociológica para mantenerlo vigente. En suma, la directiva en cuestión permite actualizar el significado de las disposiciones jurídicas para mantenerlas acordes con la realidad social, sin necesidad de introducir nuevas disposiciones legislativas.

Consecuencialista: "Procura justificar la premisa discursiva en base a que la misma implica - directa o indirectamente- consecuencias o efectos que se aprecian buenos o mejores que otros" (Vigo, 2004, p. 223). En otras palabras, el juez constitucional al momento de decidir debe preguntarse cuáles son las consecuencias que pueden tener sus interpretaciones en diversos campos que van más allá de lo estrictamente jurídico, y después de analizado esto escoger la mejor interpretación. 


\section{Argumentos interpretativos especiales para la Constitución}

Debe prevalecer el contenido finalista de la Constitución, que es garantizar la libertad y dignidad humana: esta regla de interpretación mencionada por Olano (2005, p. 68) es otra forma de enunciar el argumento interpretativo teleológico con énfasis en dos fines. Lo que sí es particular en los fines de la Constitución es que algunos de ellos son marcadamente políticos, y corresponde al tribunal constitucional manejar de manera adecuada la interpretación que realice con base en ellos.

Debe ser interpretada con un criterio amplio, liberal y práctico: directiva interpretativa que implica que al momento de hacer operativa la Constitución no debe procederse de modo "estrecho, liberal y técnico" (Linares, 2005, p. 768). Al igual que el anterior, es otra forma de reforzar la directiva teleológica mirando a la especificidad del texto constitucional.

Las palabras de la Constitución deben ser interpretadas en su sentido general y común, a menos que sea claro que el creador de la norma se refirió a un significado técnico-legal: directiva interpretativa traída por Olano (2005, p. 69), que como se colige tampoco aporta nada nuevo en el campo de estas pues es simplemente la reformulación de la directiva semántica. Además, pierde de vista el autor que algunas palabras que contiene el texto constitucional son lo suficientemente amplias y que por ello el sentido general y común del significado de estas se diluye.
Debe ser interpretada como un todo, como un conjunto armónico: "Esto significa que cuando la interpretación suscite conflicto entre las distintas partes de la Constitución, esta no resulta admisible, ya que rompe la armonía de las partes" (Olano, 2005, p. 71). De lo anterior se desprende que se está haciendo alusión al argumento sistemático, evitando que se presenten antinomias en el texto de la Constitución, por ello tampoco se consagra aquí una genuina directiva para interpretar las disposiciones jurídicas constitucionales.

Debe analizarse la situación social, política y social (sic) existente al momento de realizar la interpretación: como lo expresa Olano, este argumento es útil "sobre todo en materia de tutela y para garantizar el mínimo vital” (2005, p. 71). Sin pretender desconocer la importancia de lo comentado por el autor precitado, cabe mencionar que esta directiva no se diferencia en nada de la sociológica.

Las excepciones y los privilegios deben interpretarse con criterio restrictivo (Linares, 2005, p. 773): con esta directiva se pretende expresar que aquellos privilegios establecidos a favor de unos determinados sujetos deben interpretarse de la manera más restrictiva posible, pues todo privilegio es una desigualdad, y las desigualdades no deben ser ampliadas por medio de la interpretación constitucional. El mismo razonamiento vale para las excepciones.

Los actos públicos se presumen constitucionales: en este punto sí se encuentra una genuina directiva constitucional, referida específicamente 
a los juicios en los cuales se ejerce un control de constitucionalidad. Esta directiva es tanto como consagrar "la presunción de constitucionalidad de las leyes" (Olano, 2005, p. 72). Se busca conservar los actos realizados por los órganos competentes para ello, teniendo en cuenta que estos órganos generalmente son elegidos por el pueblo y sus actos deben ser expresión de esa legitimidad política. Además, la producción de una ley en Colombia tiene como mínimo cuatro debates e implica un desgaste por parte de los congresistas, de modo que es mejor conservar el acto que realizar una nueva ley. Gracias a esta presunción de constitucionalidad la Corte emite sentencias moduladoras para preservar el acto abrogándose muchas veces el papel de legislador positivo. En consecuencia, "la inconstitucionalidad solo debe ser planteada en los casos muy serios y abordada con la máxima de las cautelas" (Rivera, 2005, p. 996).

Los poderes públicos tienen libertad en la interpretación: esta regla, traída a colación por Olano, no implica una verdadera directiva de interpretación, solamente significa reconocer que la Constitución puede ser interpretada por cualquiera de los órganos del Estado.

Unidad de la Constitución: a criterio de Konrad Hesse "la relación e interdependencia existentes entre los distintos elementos de la Constitución obligan a no contemplar en ningún caso solo la norma aislada sino siempre además en el conjunto en el que debe ser situada" (2011, p. 67).

A propósito de esta directiva puede anotarse que no se diferencia sustancialmente del crite- rio sistemático, pues este implica que el ordenamiento jurídico es un todo unitario, y que esa unidad la garantiza precisamente la Constitución Política.

Principio de armonización: se ha expresado que este argumento comporta que "las normas constitucionales que se enfrentan en tensión recíproca tienen que ser armonizadas, puestas en concordancia la una con la otra" (Vila, 2007, p. 261). Como se puede inferir, este principio traído a colación por Vila tampoco muestra una genuina directiva de interpretación, pues hace parte de la directiva sistemática, según la cual debe haber consistencia entre las normas jurídicas, máxime si son constitucionales.

La corrección funcional: para Hesse, "si la Constitución regula de una determinada manera el cometido respectivo de los agentes de las funciones estatales, el órgano de interpretación debe mantenerse en el marco de las funciones a él encomendadas; dicho órgano no deberá modificar la distribución de las funciones a través del modo y del resultado de dicha interpretación" (2011, p. 68).

Según Vila, "el juez constitucional no puede alterar las funciones que la Constitución atribuye a cada uno de los órganos, ni modificar la distribución de funciones, so pretexto de interpretarla" (2007, p. 261). Esta directiva pretende limitar la interpretación de los tribunales constitucionales, puesto que trata de enfatizar en que las competencias atribuidas a cada órgano del Estado por la Constitución no pueden ser alteradas por vía de interpretación. Exige, pues, 
esta directiva un respeto por las funciones que expresamente ha atribuido la Constitución, lo cual es una manera de hacer énfasis en la interpretación gramatical. En similar sentido se pronuncia Javier Pérez al expresar, respecto de la corrección funcional, que implica "no desvirtuar la distribución de funciones y el equilibrio entre los poderes del Estado diseñado por la Constitución" (2005, p. 900).

Eficacia integradora de la Constitución: esta directiva aunque puede dar la impresión de apuntar a la integridad del ordenamiento jurídico, realmente comporta el que por medio de la interpretación constitucional debe tratar de mantenerse la "integración nacional".

Refiriéndose a este criterio Hesse afirma: "Si la Constitución se propone la creación y el mantenimiento de la unidad política ello exige otorgar preferencia en la solución de los problemas jurídico-constitucionales a aquellos puntos de vista que promuevan y mantengan dicha unidad" (2011, p. 69). ${ }^{9}$

Como se colige, se trata de medir las consecuencias políticas que pueda tener determinada interpretación, y por ello si esta conduce a efectos negativos en lo económico, social o político debe ser descartada. De este modo, debe preferirse la interpretación que no traiga consecuencias que afecten la integración de la nación.

Interpretación de acuerdo con tratados internacionales sobre derechos: esta directiva de inter-

9 De manera similar lo expresa Vila (2007, p. 262). pretación no es genuinamente constitucional. Puede entenderse que hace parte de la directiva sistemática, pues si los tratados sobre derechos humanos ratificados por el Estado hacen parte del bloque de constitucionalidad, como sucede en Colombia, al momento de interpretar la Constitución conforme a dichos tratados se está interpretando de manera sistemática. Esto debe hacerse en procura de garantizar el efecto útil de los tratados.

Principio de la motivación adecuada: este principio mencionado por Olano (2005, p. 80) no es un verdadero criterio interpretativo, porque la motivación de las sentencias es precisamente lo que permite plasmar la interpretación realizada. En similar sentido se pronuncia Vigo cuando menciona como directiva "la fundamentación apropiada de las decisiones" (2004, p. 174).

Principio de la Corte Interamericana de Derechos Humanos (Corte IDH) como intérprete constitucional: esta directiva es referida por Olano (2005, p. 78), sin embargo, más que una verdadera directiva se trata es de reconocer la autoridad que tiene dicha institución para la interpretación de los derechos humanos.

Principio de la realidad constitucional: Olano menciona que dicha directiva se desprende del artículo 53 de la Constitución Política de Colombia. Este criterio implica que al momento de interpretar se deben tener en cuenta los factores sociales que pueden influir en la decisión.

Principio de prevalencia del derecho sustancial: este principio lo cita Olano (2005, p. 82) y lo des- 
prende del artículo 228 de la Constitución Política. Lo que se busca con este argumento es evitar que los formalismos puedan ocasionar serias vulneraciones al derecho sustancial de los habitantes del Estado. De ahí que esta tampoco sea una verdadera y genuina directiva de interpretación constitucional, puesto que es la directiva teleológica la que se está consagrando.

Principio de supremacía constitucional y de la fuerza vinculante de esta: al igual que el anterior, el presente principio es mencionado por Olano (p. 88) quien parece seguir al respecto los planteamientos de Hesse, para quien además este criterio implica: "dar preferencia en la solución de los problemas jurídico-constitucionales a aquellos puntos de vista que ayuden a las normas de la Constitución a obtener la máxima eficacia, bajo las circunstancias de cada caso" (2011, p. 69).

Ciertamente, tampoco este es un novedoso criterio de interpretación pues hace referencia, en últimas, a la directiva sistemática en donde es un presupuesto que la Constitución Política es la cúspide del ordenamiento jurídico y por ende es la de mayor jerarquía. Así, la supremacía de la Constitución "tiene, entre otras, las siguientes implicaciones en la labor interpretativa: todos los actos y hechos que se realicen dentro del territorio nacional, provengan de particulares o de autoridades, deben estar de acuerdo o fundados en la Constitución" (Arteaga, 2005, p. 68).

Principio de la concordancia práctica o de coherencia lógica del orden: para Hesse "Los bienes jurídicos constitucionalmente protegidos deben ser coordinados de tal modo en la solución del problema que todos ellos conserven su entidad" (2011, p. 67). ${ }^{10}$ Es justo decir que esta directiva nada aporta de nuevo al panorama de la interpretación jurídica constitucional, puesto que es una reformulación del criterio sistemático, atendiendo a una particularidad de la Constitución.

Principio favor constitutionae: conforme a este principio se deben interpretar las disposiciones normativas de la manera más acorde con la Constitución (Olano, 2005, p. 95). Una vez más se encuentra un criterio que hace alusión a la directiva sistemática. Esto quiere decir que interpretar las demás disposiciones de manera acorde con la Constitución es una forma de conservar el ordenamiento jurídico y evitar las contradicciones en este.

Principio normativo conservacionista o de la conservación del derecho: según Olano, en virtud de este principio "la Corte Constitucional no puede excluir una norma legal del ordenamiento jurídico, por vía de la declaración de inexequibilidad, cuando existe, por lo menos, una interpretación de la misma que se aviene con el texto constitucional" (2005, p. 95). Este criterio implica entonces una manera de interpretar típicamente constitucional, en la cual se busca conservar la disposición jurídica sometida a una cuestión constitucional. De este modo es que se han justificado las declaraciones de exequibilidad condicionada.

10 Del mismo modo, Olano reproduce este criterio en el ámbito colombiano (p. 93). 
Principio In Dubio Pro Libertate: para Olano este principio implica que "atendiendo a las diferentes interpretaciones de una disposición legal, el juez constitucional deberá optar por aquella que garantice con mayor amplitud el ámbito de la libertad en cuestión" (2005, p. 103). Conforme a esta directiva la libertad, que es uno de los pilares de una Constitución Política de un Estado democrático, siempre debe interpretarse para favorecer su ejercicio.

Este argumento se corresponde muy bien con lo que se ha denominado criterio teleológico, solo que con esta directiva se refuerza lo importante de perseguir la libertad. En este sentido lo toma Torres del Moral (aunque él lo denomina interpretación favorable a la libertad) cuando afirma que "Es esta, la de los derechos y libertades, una de las áreas constitucionales en las que tiene mayor aplicación la interpretación teleológica, de conformidad con el principio universalmente admitido (y evocado por el Tribunal Constitucional) de la interpretación más favorable a la libertad y a la mayor efectividad del derecho" (2005, p. 1300).

Esta idea llevó a Torres del Moral a sostener que "en un Estado social y democrático de derecho la libertad es la regla y su limitación la excepción" (2005, p. 1303).

\section{Optimización de la eficacia jurídica de la Consti-} tución: esta directiva implica "que se privilegien aquellas opciones hermenéuticas que maximicen la eficacia de la Constitución" (Vigo, 2004, p. 107). En materia de interpretación no aporta nada nuevo, pues es solo una manera de reafirmar el papel angular que tiene el texto constitu- cional. En el contexto colombiano, esto conlleva decir que debe aplicarse el artículo $4^{\circ}$ de la Constitución y, por ende, mantener la supremacía de la Carta en el ordenamiento jurídico.

La Constitución como sistema: "Una proyección de esta directiva consiste en atribuir o desechar significados a un enunciado constitucional según la localización topográfica que el mismo tiene en el texto" (Vigo, 2004, p. 117). Como fácilmente se deduce, esta directiva de interpretación propuesta por Vigo tampoco aporta nada novedoso, es solo una manifestación específica de la directiva sistemática.

La máxima funcionalidad del régimen político: la Constitución Política, al ser creada por el poder constituyente, es una manifestación política de un determinado conglomerado social, razón por la cual las disposiciones jurídicas consagradas en el texto constitucional son reflejo de posiciones políticas. Por ello la interpretación constitucional "debe orientarse a conservar y fortalecer aquella unidad y régimen político que la sociedad ha establecido en la ley fundamental" (Vigo, 2004, p. 133). Esta directiva es una manera sofisticada de enunciar el criterio teleológico, ya que esa máxima funcionalidad del régimen político es uno de los fines que se persiguen por medio de las disposiciones jurídicas constitucionales.

\section{Consolidación de los valores constitucionales:} sin pretender entrar en la polémica acerca de si las constituciones consagran o no valores, si hay o no jerarquía entre ellos, etc., se pretende solo mostrar cómo la doctrina ha tenido en cuenta los valores al momento de interpretar 
constitucionalmente. Por ello "se ha destacado que la Constitución expresa y sirve a un sistema o código de valores sustanciales (Grundwerte) comunes que deben ser tenidos en cuenta a la hora de aplicar dicha norma superior del ordenamiento jurídico" (Vigo, 2004, p. 142).

Atender a las consecuencias sociales: "Pesa sobre el intérprete la responsabilidad de buscar la justicia en el caso, pero en esta dilucidación no pueden quedar afuera las exigencias de toda la sociedad" (Vigo, 2004, p. 152). Esta directiva es similar a la planteada en el numeral 2.5, según el cual debe analizarse la situación social, política y social (sic) existente al momento de realizar la interpretación. Como se anotó allí, este canon es una manifestación del criterio sociológico, sin embargo, lo novedoso en Vigo es que apunta hacia la equidad, cuando hace alusión a "la justicia en el caso".

Fidelidad no estática al poder constituyente: esta directiva es una manera elegante de mencionar la directiva histórica, es decir, es la directiva histórica reformulada para los fines de la Constitución. Lo que se pretende es que al momento de argumentar constitucionalmente, se tenga en cuenta tanto el contexto histórico del constituyente y su voluntad como el contexto histórico del momento de la interpretación y la voluntad objetivada de la disposición constitucional. Por ello la "lectura integral y axiológica del texto constitucional es una vía idónea para cumplir ese doble cometido, es decir, por un lado el respeto a esa voluntad pretérita y, por el otro, una respuesta apropiada al reclamo presente y futuro" (Vigo, 2004, p. 161).

\section{Esfuerzo coordinador del derecho constitucional} interno con el derecho comunitario: supone esta directiva que la concepción clásica de soberanía ha cambiado, que a la par del Estado soberano se han colocado normas de índole internacional que pueden aplicarse en el ordenamiento jurídico estatal. De este modo "en orden a ir consolidando la vigencia del derecho comunitario, como a precisar sus características, les cabe tanto a los jueces comunitarios como también a los nacionales, cumplir un papel destacado" (Vigo, 2004, p. 186). Esta directiva es la misma sistemática, pues tener conformidad con normas internacionales garantiza unidad, coherencia y plenitud.

Principio de incongruencia inconstitucional: este canon parte de presuponer la existencia de incongruencias en la Constitución. Deficiencias que son atribuibles al creador del texto de la Constitución y a aquellos que la reforman. Como el operador jurídico tiene el deber de fallar sin importar las incongruencias que existan, debe dotársele de medios para que pueda hacerlo.

Así, lo que se pretende con este principio es hacer evidente esta situación y que "debe procurarse que se deje de aplicar o tenga que sacrificarse la parte que sea menos importante o que tenga consecuencias menos peligrosas o nocivas, la que no atente contra el principio de seguridad, contradiga o rompa ciertos principios" (Arteaga, 2005, p. 74).

Principio de permanencia constitucional: conforme a esta directiva la Constitución fue creada con vocación de permanencia en el tiempo, y 
por ende debería ser inderogable. Esta directiva adquiere importancia sobre todo en el tema de la reforma constitucional, la cual es legítima si respeta los parámetros establecidos en los artículos que la consagran. Sin embargo, el poder de reforma no es ilimitado y "nunca supone o puede significar la abrogación o anulación de la Constitución o su sustitución total por otra nueva" (Arteaga, 2005, p. 84).

Principios de generalidad y exclusividad: conforme a esta directiva "Cuando una facultad o atribución se concede a un poder u órgano en términos generales y a otros en forma privativa o exclusiva, debe prevalecer esta última sobre aquella" (Arteaga, 2005, p. 87). Esta no es una genuina directiva de argumentación constitucional, es solo la aplicación de la máxima según la cual la regla especial prevalece sobre la general.

Principio del silencio de la Constitución: esta directiva está orientada a los órganos del poder público, pues ellos solo pueden realizar aquello que se encuentra expresamente ordenado. De este modo, "Tratándose de poderes y autoridades, cuando la Constitución guarda silencio es que niega. El silencio debe interpretarse como prohibición" (Arteaga, 2005, p. 91).

\section{Principio de que todo poder es completo en sí} mismo: de acuerdo con esta directiva mencionada por Arteaga se establece que "Cuando se trata de cualquiera de los poderes cuya existencia esté prevista por la Constitución, debe partirse del supuesto de que contiene en sí todos los elementos para subsistir, para hacer operante las facultades que le han sido conferidas y para defender su campo de acción" (2005, p. 92). Por considerarse solo una manifestación de la división de los órganos del poder público, no se estima que sea una directiva argumentativa.

\section{Criterio de la escindibilidad de las disposiciones} interpretadas: "Que permite segmentar el análisis, a fin de preservar la parte impoluta del texto impugnado y salvar sus efectos jurídicos, reduciendo la anulación a la parte afectada" (Gómez, 2008, p. 230).

Criterio del magisterio constitucional: "Que permite generar pautas para la intelección de todo el ordenamiento jurídico" (Gómez, 2008, p. 230).

Principio pro homine o pro persona: esta directiva está estrechamente relacionada con los derechos humanos, en aras de darles una mayor efectividad, y ello "supone la necesidad de optar por la interpretación más favorable de entre todas las posibles y, por tanto, la interpretación restrictiva (...) de las normas limitadoras" (Aba, 2011, p. 390).

La directiva en comento invita al operador constitucional a buscar el sentido más favorable para el ser humano como titular de derechos humanos. Así, "la interpretación del ordenamiento de acuerdo con los derechos fundamentales exige interpretar estos puesto que hay que determinar cuál es su sentido más favorable" (Pérez, P., 2005, p. 906). Una manera de concretarla está relacionada con la limitación de los poderes de los órganos del Estado, por ello se dice que "Cuando se pre- 
sente una situación en la que exista un conflicto entre los derechos humanos de la persona con las competencias y atribuciones de los órganos de poder otorgados por la propia Constitución, el intérprete constitucional deberá inclinarse por aquellos" (Rivera, 2005, p. 996).

Conforme a la doctrina, el principio pro persona tiene dos variantes: (i) la preferencia interpretativa y (ii) la preferencia de normas (Carpio, 2005, p. 329). Por medio de la preferencia interpretativa se busca la interpretación que sea más favorable al ser humano. En esta variante se incluye el principio favor libertatis como perteneciente al principio pro personae; con base en este las limitaciones establecidas a los derechos humanos no se deben interpretar de manera extensiva. Y también se incluye el principio de protección a las víctimas o el principio favor debilis. Bidart Campos establece "Que en la interpretación de situaciones que comprometen derechos en conflicto es menester considerar especialmente a la parte que, en su relación con la otra, se halla situada en inferioridad de condiciones 0 , dicho negativamente, no se encuentra realmente en pie de igualdad con la otra" (citado por Carpio, 2005, p. 329).

Con relación a la variante de la preferencia de normas, dado que para un caso concreto sean aplicables dos normas y una de ellas sea más favorable a los derechos humanos, debe aplicarse esta sin importar su jerarquía.

Es de anotar que para algún sector de la doctrina el principio pro persona es más amplio, dado que engloba, entre otros, los siguientes: princi- pio favor libertatis; in dubio pro operario (para los derechos laborales); principio pro actione (relacionado con la tutela jurisdiccional efectiva) (Carpio, 2005, p. 331 y ss.).

Con respecto a la jurisprudencia se ha utilizado dicha directiva expresando que: "si bien en la propia práctica de la tutela de los derechos fundamentales se puede apreciar un uso variado de las distintas teorías de la interpretación constitucional, esto no es perjudicial para el desarrollo constitucional, en la medida en que la modificación de la jurisprudencia se encuentre acorde con el principio humanista del in dubio pro homine" (Landa, 2005, p. 750).

En otras palabras, la directiva de interpretación pro personae pretende maximizar la protección del ser humano en los diversos ámbitos donde los derechos humanos pueden ser limitados por los operadores jurídicos. Por ello pretende que al momento de interpretar o de aplicar las disposiciones jurídicas se busque lo más favorable al ser humano.

\section{CRÍTICA A LAS DIRECTIVAS DE INTERPRETACIÓN CONSTITUCIONAL CREADAS POR LA DOGMÁTICA JURÍDICA}

El aspecto central de la crítica va dirigida al papel de las directivas de interpretación, pues "La existencia de un método de interpretación no representa sino una posibilidad más de interpretación (a mayor número de métodos, mayor número de posibilidades de significación). Todos los 
métodos de interpretación no han representado sino una significación posible" (Tamayo, 2005, p. 1184).

De la anterior cita se puede inferir que si las directivas otorgan un significado posible, determinar cuál va a prevalecer será entonces un mero acto de voluntad, y por ende estas no sirven para prever cuál va a ser la decisión que tomará el operador jurídico. Por esto se suscribe la siguiente idea "Este permanente ir y venir entre criterios interpretativos que apuntan en direcciones muchas veces opuestas entre sí resulta, como mínimo, muy preocupante" (Gargarella, 2011, p. 56). Y es preocupante por la existencia de gran cantidad de directivas constitucionales, las cuales permiten que el operador jurídico pueda sustentar con apariencia de juridicidad las más variadas opiniones.

Por ello Sagüés expresa que esta cantidad de directivas trae como secuela que "el producto final [sea] decididamente no pronosticable" (citado por Gargarella, 2011, p. 57). Y es cierto que resulta difícil prever cuáles serán las decisiones, puesto que las directivas son muchas, y no existe una jerarquía entre ellas, ni un método para usarlas.

Por estos dos motivos (ir y venir de los criterios y la imposibilidad de pronosticar) Gargarella va a afirmar "la existencia de un maltrato institucional por parte de la esfera más alta de la justicia, hacia los ciudadanos" (2011, p. 58). Si bien el autor citado se refiere a la situación existente en Argentina, la doctrina constitucional colombiana debe preguntarse hasta qué punto la si- tuación en el Estado de Colombia es similar. En este punto es importante anotar que la vaguedad del lenguaje le otorga amplias ventajas a la rama judicial para maniobrar con el derecho, pero ello no la puede llevar a la concentración del poder, pues todo exceso de poder venga de donde venga debe ser rechazado.

Este irrespeto institucional se materializa porque

La Corte puede llegar a una conclusión determinada o a otra exactamente contraria a la anterior, dependiendo de cuál sea el criterio interpretativo que elija priorizar. Es decir, la Corte puede hacer casi lo que quiere con el caso que tiene frente a sí, gracias a la enorme variedad de parámetros interpretativos a los que puede, indistintamente, apelar (Gargarella, 2011, p. $60)$.

Inclusive, para Gargarella (2011, p. 61), aunque se diga que solo se utilizará una sola directiva, la situación no cambiaría, pues con una sola directiva se pueden justificar resultados contradictorios.

Todo esto conlleva a que el tribunal constitucional tenga mayor discrecionalidad que cualquier otro juez, y en algunos casos más que el ejecutivo y el legislativo pues estos actúan con base en una competencia reglada por la Constitución y la legislación, mientras que la Corte Constitucional determina por vía de interpretación a todos los demás órganos del Estado. Cabe entonces preguntar: ¿quién limita al determinador? En otras palabras, las directivas de interpretación constitucional eventualmente pueden justificar 
una discrecionalidad que raye con lo arbitrario y lo meramente opinable.

Una manera de disminuir las consecuencias contraproducentes de las directivas de interpretación es acudiendo a la opinión pública. En concepto de Zaldivar, "debe reconocerse que el único límite y control eficaz que ha funcionado, a efecto de lograr que los jueces constitucionales cumplan con un método jurídico suficientemente razonado, es el peso de la opinión pública" (2005, p. 1406). Aunque la propuesta es interesante, es válido preguntarse: ¿cómo puede desempeñar su papel la opinión pública ante la gran cantidad de casos existentes?, ¿cómo hacer jurídicamente vinculantes los controles realizados por los ciudadanos?, ¿es posible fácticamente que este control sea realizado por los ciudadanos?, ¿están interesados los ciudadanos en encargarse de esta tarea?, ¿no recaería este control, en últimas, en una forma de justicia mediática? Ante tantas interrogantes podría afirmarse que acudir a la opinión pública trae más perjuicios que beneficios, teniendo en cuenta que esta puede tener intereses abiertamente contrarios a la Constitución, puede estar dividida y, además, ser maleable.

Por otra parte, no se aboga en este artículo por la existencia de una única respuesta correcta. Se pretende expresar que las directivas de interpretación no son garantes de resultados inequívocos y medianamente predecibles; dan la posibilidad de escoger entre múltiples significados; y la existencia de tantas directivas de interpretación constitucional más que ayudar termina confundiendo. Respecto de este último punto la doctrina ha generado una gran cantidad de directivas de interpretación sin rigurosidad, duplicados de otras directivas, y parece estar creando directivas por las directivas mismas sin tener en cuenta el objeto de ellas. Son directivas que por pretender novedad terminan oscureciendo la interpretación constitucional; en otras palabras, como hacen algunos comerciantes, le apuntan a la mayor cantidad de directivas y no a la calidad de ellas.

Se ha pretendido paliar esta deficiencia expresando que lo más importante es la razonabilidad de la decisión o su control de manera racional. Sin embargo, cabe anotar: si para un caso concreto se pueden utilizar dos directivas, las cuales llevan a resultados contradictorios, y el tribunal constitucional escoge una de ellas para sustentar su decisión, en una votación con cinco votos a favor y cuatro salvamentos de voto ¿se puede hablar de decisión razonable?, ¿no sería igual de razonable la decisión amparada por la directiva derrotada?

Lo anterior permite afirmar que "estos métodos son política jurídica y no ciencia del derecho" (Tamayo, 2005, p. 1185). Y es así por depender, en últimas, de una votación que expresa la voluntad política y jurídica de unos magistrados que operan con un texto igualmente político y jurídico como lo es la Constitución. Por ser estas directivas, finalmente, una manera de política jurídica, no es gratuito afirmar "que la personalidad y la idiosincrasia, principalmente de los jueces, en las tareas de la decisión jurídica es fundamental" (Jiménez, 2011, p. 236). Y es fundamental porque estos elementos van a ser decisivos al momen- 
to de realizar la interpretación constitucional, ya que el juez no puede separarse de su subjetividad al momento de decidir. Por esto se afirma que "La ideología del intérprete se proyecta necesariamente en el momento de la aplicación de las normas. No es admisible el subjetivismo, mientras que un cierto margen de subjetividad es inevitable y necesario" (Lorca, 2011, p. 312).

Se ha buscado matizar el carácter político de la interpretación constitucional expresando que "No se trata pues de una justicia política ni del juez político, sino los efectos políticos, muy significativos en la época contemporánea de la actividad interpretativa (e integradora), de los tribunales constitucionales" (Fix-Zamudio, 2005, p. 564). Expresar que no se trata del juez político ni de justicia política pero sí de efectos políticos, no es sino un modo subrepticio de hablar del juez político, pues aquel cuya actividad tiene efectos políticos es porque está operando políticamente, y quien opera políticamente es un agente político.

Por su parte, Pablo Pérez expresa que los jueces constitucionales no deben realizar "políticas judiciales", y que la manera de cumplir con la dimensión positiva de la interpretación constitucional es "guiando su labor de acuerdo con el principio del favor libertatis" (2005, p. 907). Sin embargo, se estima que con este principio no se logra un mejor resultado, pues su significado es tan amplio que no limita el poder decisorio de los tribunales constitucionales. A favor de la libertad se pueden exceder las competencias, pues como él mismo lo anota "el intérprete puede caer también en la tentación de ser él quien define los contenidos de los derechos sin otro criterio que su discrecionalidad" (2005, p. 908).

Una crítica a las directivas de interpretación constitucional es importante pues "Si el método utilizado resiste un análisis riguroso técnico-jurídico entonces la justicia constitucional estará debidamente legitimada y justificada" (Zaldivar, 2005, p. 1398). Así, si existe una claridad en la dogmática jurídica acerca del tema en estudio se podrá avanzar en la razonabilidad de las sentencias de los jueces constitucionales, en el control por parte de la doctrina y en la previsibilidad de las decisiones de tutela o de control de constitucionalidad. Lo que cabe preguntarse y debe ser objeto de investigación por parte de la dogmática jurídica es: ¿en el Estado de Colombia la interpretación constitucional sí se encuentra debidamente legitimada y justificada?, ¿cómo medir ante esta variedad de sentencias la legitimación del tribunal constitucional? Como se sabe, las respuestas no son de color blanco o negro, sino que tienen matices.

Por su parte, Vigo llegó a mencionar algunos de los aspectos que pueden distorsionar el papel de la Constitución, de los tribunales constitucionales y, por ende, de la interpretación constitucional:

- Que el intérprete le haga decir a la Constitución lo que él quiere que diga o le haga decir mucho más de lo que ella efectivamente dice.

- Por el uso excesivo de la Constitución (imperialismo constitucional) opacar el papel de las otras fuentes del derecho. 
- Hiperconstitucionalización judicial.

- Por tratar acerca de asuntos que son opinables se corre el riesgo de que "la concepción del intérprete se convierta en concepto constitucional (2005, p. 1356).

Sin embargo, Vigo cree que las directivas constitucionales son un remedio para estos problemas, pero esto no es totalmente cierto, pues tanta abundancia de directivas permite justificar lo que el operador jurídico constitucional desee; lo cual lleva de nuevo al carácter político de la interpretación constitucional y esto conduce "a la paradójica conclusión de que en un máximo de juridificación la solución para una correcta interpretación constitucional es política e imposible de formalizar normativamente, pues no cabe establecer límites expresos a la acción de los tribunales constitucionales fuera de los que marcan su apego a la Constitución y a su propia ley reguladora" (Canosa, 2005, p. 239).

Con base en la anterior cita, se puede establecer que la existencia de tantas directivas realmente no limita ni garantiza interpretaciones constitucionalmente correctas, no hay norma que obligue a los tribunales a valerse de dicho arsenal interpretativo.

Otro punto importante es que la reforma constante de la Constitución no permite consolidar una línea o líneas interpretativas claras. Si la estructura del Estado cambia, si los derechos consagrados tienen variaciones o si las funciones de los órganos sufren alteraciones, necesariamente la interpretación constitucional tendrá que cambiar para estar acorde con la nueva rea- lidad del texto constitucional. Por ello,

Solo puede haber interpretación de la Constitución si queda clara la distinción jerárquica entre poder constituyente y poder constituido legislativo. Si como ocurrió históricamente en Francia, el constituyente no es más que el poder legislativo de los días de fiesta, la interpretación constitucional no tiene cabida, pues se funda en la supremacía de la Constitución sobre la ley (Canosa, 2005, p. 254).

Otro aspecto a criticar es la idea de justicia. Se ha expresado que "La misión del juez constitucional va más allá de la realización de inferencias correctas; no puede cerrar los ojos al análisis de la justicia de la conclusión" (Carmona, 2005, p. 296). Es uno de los puntos más arduos para la interpretación constitucional, en el sentido de que aún no existe un consenso acerca de lo que es la justicia, y a pesar de que algunas directivas apuntan hacia ella, la vaguedad de la expresión seguirá afectando la interpretación de esta. Y ante la falta de este consenso se van a terminar imponiendo las concepciones de justicia de los magistrados, amparadas en las directivas, que no necesariamente son las del pueblo.

Un aspecto que no deja de llamar la atención es que algunos doctrinantes apelen a la sensibilidad para la interpretación constitucional. "La elección de las premisas a nivel constitucional involucra elementos políticos, económicos, sociales y culturales, que solo pueden percibirse a través de la experiencia y sensibilidad del juez constitucional" (Carmona, 2005, p. 294). También se ha expresado "que la interpretación de 
las disposiciones constitucionales requiere por parte del intérprete o aplicador, una particular 'sensibilidad', que le permita captar la esencia, penetrar en la entraña misma y comprender la orientación de las disposiciones fundamentales" (Carpizo y Fix-Zamudio, 2005, p. 398). ${ }^{11}$

Esta referencia a la sensibilidad es de un modo u otro una alusión a los aspectos subjetivos del juez al tomar la decisión, es apelar a su conciencia para que tome la mejor decisión y pueda comprender de la mejor manera el texto constitucional. ¿Será esta sensibilidad de los jueces una garantía para hallar respuestas lo más correctas posibles?, ¿será esto un modo de autocontrol de los jueces?, y ¿qué pasa si el juez no es sensible al escoger las directivas de interpretación constitucional?

\section{CONCLUSIONES}

- Se han creado directivas de interpretación constitucional como si fuera una producción industrial, perdiéndose su rigurosidad y generándose directivas espejo, es decir, directivas que son en el fondo lo mismo que otras pero con diferente nombre.

- Las directivas son tan diversas que pueden dar entrada libre a casi todas las interpretaciones posibles, pues sirven de argumentos que al no tener jerarquía pueden ser escogidos por el in-

11 "Ha determinado la necesidad de que los jueces constitucionales estén dotados de una sensibilidad política y social que les permita descubrir en las disposiciones fundamentales, los principios y valores de una comunidad política en un momento determinado" (Fix-Zamudio, 2005, p. 564). térprete según su interés concreto, para terminar prefiriendo su interpretación por vía de voluntad maquillada de argumentos jurídicos, hasta el punto de poner en duda el control de la arbitrariedad que se utiliza en ocasiones para justificarlas, en este caso más bien podrían ser las directivas el fundamento de la arbitrariedad misma.

- Muchas de las que se hacen llamar directivas de interpretación constitucional no son genuinas directivas, sino juegos de palabras de la doctrina que esconden otra directiva que le sirve de sustento.

- Las directivas tradicionales de interpretación no deben ser dejadas de lado, pero tampoco son las únicas a utilizar al momento de enfrentar el texto constitucional, pues por las características de este son necesarias auténticas directivas de interpretación constitucional.

- Un adecuado desarrollo de las directivas de interpretación constitucional puede conducir a matizar el carácter político y la subjetividad del intérprete constitucional, pues aunque no conducirán a una única respuesta correcta sí permitirán prever las decisiones judiciales.

- Parte de la doctrina ha contribuido, por la falta de rigor en el manejo de las directivas de interpretación constitucional, a oscurecer la manera en que se determina o se debe determinar el significado del texto constitucional. 


\section{Referencias}

Aba, A. (2011). Interpretación constitucional e interpretación de la Constitución. En J. Espinoza de los Monteros y J. R. Narváez H. (Coords.), Interpretación jurídica: modelos históricos y realidades (págs. 381-398). México, D. F.: Universidad Nacional Autónoma de México.

Aguiló, J. (Abril, 1997). Independencia e imparcialidad de los jueces y argumentación jurídica. Isonomía, (6), 71-79.

Alexy, R. (2007). Teoría de la argumentación jurídica. Madrid: Centro de Estudios Políticos y Constitucionales.

Aragón, M. (2005). La interpretación de la Constitución y el carácter objetivado del control constitucional. En E. Ferrer Mac-Gregor (Ed.), Interpretación constitucional (t. I, págs. 1159). México, D. F.: Porrúa.

Arango, R. (Noviembre, 1993). Jurisdicción e interpretación constitucional. Revista de Derecho Público, (4), 31-38.

Arteaga, E. (2005). La interpretación constitucional. En E. Ferrer Mac-Gregor (Ed.), Interpretación constitucional (t. I, págs. 61-120). México, D. F.: Porrúa.

De Asís Roig, R. (1995). Jueces y normas: la decisión judicial desde el ordenamiento. Madrid: Marcial Pons.

De Asís Roig, R. (2008). Sobre la interpretación de la Constitución. En E. Ferrer Mac-Gregor y A. Zaldívar Lelo de Larrea (Coords.), La ciencia del derecho procesal constitucional. Estudios en homenaje a Héctor Fix-Zamudio en sus cincuenta años como investigador del derecho. Interpretación constitucional y jurisdicción electoral (t. VI, págs. 211-230).

Betegón, J. et al. (1997). Lecciones de teoría del derecho. Madrid: McGraw Hill.

Canosa, R. (2005). Interpretación constitucional y voluntad democrática. En E. Ferrer Mac-Gregor (Ed.), Interpretación constitucional (t. I, págs. 237-259). México, D. F.: Porrúa.

Carmona, J. (2005). Algunos aspectos sobresalientes de la interpretación judicial. En E. Ferrer Mac-Gregor (Ed.), Interpretación constitucional (t. I, págs. 281-319). México, D. F.: Porrúa.

Carpio, E. (2005). La interpretación de los derechos fundamentales. En E. Ferrer Mac-Gregor (Ed.), Interpretación constitucional (t. I, págs. 281-319). México, D. F.: Porrúa.

Carpizo, J. y Fix-Zamudio, H. (2005). Algunas reflexiones sobre la interpretación constitucional en el ordenamiento mexicano. En E. Ferrer Mac-Gregor (Ed.), Interpretación constitucional (t. I, págs. 385-438). México, D. F.: Porrúa.

Fix-Zamudio, H. (2001). Lineamientos esenciales de la interpretación constitucional. En E. Ferrer Mac-Gregor (Ed.), Interpretación constitucional (t. I, págs. 521-575). México, D. F.: Porrúa. 
Gargarella, R. (2011). De la alquimia interpretativa al maltrato constitucional. En J. R. Narváez y J. Espinoza de los Monteros (Coords.), Interpretación jurídica: modelos históricos y realidades (págs. 53-67). México, D. F.: Universidad Nacional Autónoma de México.

García, A. (2011). La revancha neoconstitucionalista de Grecia contra Roma. En J. R. Narváez y J. Espinoza de los Monteros (Coords.), Interpretación jurídica: modelos históricos y realidades (págs. 141-156). México, D. F.: Universidad Nacional Autónoma de México.

Gómez, L. (2008). Hermenéutica jurídica. La interpretación a la luz de la Constitución. Bogotá, D. C.: Ediciones Doctrina y Ley Ltda.

Guastini, R. (2010). Teoría e ideología de la interpretación constitucional. Madrid: Trotta.

Hesse, K. (2011). Escritos de derecho constitucional. Madrid: Centro de Estudios Políticos y Constitucionales.

Huerta, C. (2008). Interpretación constitucional. En E. Ferrer Mac-Gregor y A. Zaldívar Lelo de Larrea (Coords.), La ciencia del derecho procesal constitucional. Estudios en homenaje a Héctor Fix-Zamudio en sus cincuenta años como investigador del derecho. Interpretación constitucional y jurisdicción electoral (t. VI, págs. 281-323). México, D. F.: Universidad Nacional Autónoma de México. Instituto Mexicano de Derecho Procesal Constitucional Marcial Pons.
Huerta, C. (2009). Teoría del Derecho. Cuestiones relevantes. México D. F.: Universidad Nacional Autónoma de México.

Jiménez, R. (2011). La interpretación de las cláusulas morales del derecho. En J. R. Narváez H. y J. Espinoza de los Monteros (Coords.), Interpretación jurídica: modelos históricos y realidades (págs. 215-239). México, D. F.: Universidad Nacional Autónoma de México.

Landa, C. (2005). Teorías de la interpretación constitucional. En E. Ferrer Mac-Gregor (Ed.), Interpretación constitucional (t. II, págs. 731750). México, D. F.: Porrúa.

Linares, S. (2005). La interpretación constitucional. En E. Ferrer Mac-Gregor (Ed.), Interpretación constitucional (t. II, págs. 759-778). México, D. F.: Porrúa.

López Medina, D. E. (2005). Hermenéutica legal y hermenéutica constitucional. Antecedentes históricos y perspectivas contemporáneas. En E. Ferrer Mac-Gregor (Ed.), Interpretación constitucional (t. II, págs. 779793). México, D. F.: Porrúa.

López, D. (2008). La letra y el espíritu de la ley. Bogotá, D. C.: Universidad de los Andes.

Lorca, M. (2011). Interpretación jurídica e interpretación constitucional. La interpretación de derecho en manos de la Corte Suprema argentina. En J. R. Narváez H. y J. Espinoza de los Monteros (Coords.), Interpretación jurídica: modelos históricos y realidades (págs. 241-313). México, 
D. F.: Universidad Nacional Autónoma de México.

Monroy, M. (2002). La interpretación constitucional. Bogotá, D. C.: Ediciones Librería del Profesional.

Olano García, H. (2005). Interpretación y dogmática constitucional. Bogotá: Ediciones Doctrina y Ley.

Pérez, J. (2005). La interpretación de la Constitución. En E. Ferrer Mac-Gregor (Ed.), Interpretación constitucional (t. II, págs. 881-901). México, D. F.: Porrúa.

Pérez, P. (2005). La interpretación de los derechos fundamentales. En E. Ferrer Mac-Gregor (Ed.), Interpretación constitucional (t. II, págs. 903-918). México, D. F.: Porrúa.

Prieto, L. (2005). Notas sobre la interpretación constitucional. En E. Ferrer Mac-Gregor (Ed.), Interpretación constitucional (t. II, págs. 919948). México, D. F.: Porrúa.

Quiroga, A. (2005). La interpretación constitucional. En E. Ferrer Mac-Gregor (Ed.), Interpretación constitucional (t. II, págs. 949-966). México, D. F.: Porrúa.

Rivera, J. (2005). La interpretación constitucional. En E. Ferrer Mac-Gregor (Ed.), Interpretación constitucional (t. II, págs. 979-1005). México, D. F.: Porrúa.
Ruiz, R. (s. f.). La distinción entre reglas y principios y sus implicaciones en la aplicación del derecho. Revista URBE et IUS, (20), 1-14.

Savigny, F. (1979). Metodología jurídica. Buenos Aires: Ediciones Depalma.

Tamayo, R. (2005). La interpretación constitucional. En E. Ferrer Mac-Gregor (Ed.), Interpretación constitucional (t. II, págs. 1157-11983). México, D. F.: Porrúa.

Toller, F. (2005). Resolución de los conflictos entre derechos fundamentales. En E. Ferrer Mac-Gregor (Ed.), Interpretación constitucional (t. II, págs. 1199-1284). México, D. F.: Porrúa.

Torres del Moral, A. (2005). Interpretación teleológica de la Constitución. En E. Ferrer MacGregor (Ed.), Interpretación constitucional (t. II, págs. 1285-1310). México, D. F.: Porrúa.

Vega, J. (2005). Seguridad jurídica e interpretación constitucional. En E. Ferrer Mac-Gregor (Ed.), Interpretación constitucional (t. II, págs. 1311-1330). México, D. F.: Porrúa.

Vila Casado, I. (2007). Fundamentos del derecho constitucional contemporáneo. Bogotá: Legis.

Vigo, R. (2004). Interpretación constitucional. Buenos Aires: Lexis Nexis.

Vigo, R. (2005). Directivas de la interpretación constitucional. En E. Ferrer Mac-Gregor 
(Ed.), Interpretación constitucional (t. II, realista). En E. Ferrer Mac-Gregor (Ed.), Interprepágs. 1331-1368). México, D. F.: Porrúa.

tación constitucional (t. II, págs. 1369-1390). México, D. F.: Porrúa.

Wróblewski, J. (1988). Constitución y teoría ge-

neral de la interpretación jurídica. Madrid: Zaldívar, A. (2005). La naturaleza de la interpreCivitas. tación constitucional. En E. Ferrer Mac-Gregor (Ed.), Interpretación constitucional (t. II,

Würtenberger, T. (2005). Interpretación del depágs. 1391-1419). México, D. F.: Porrúa.

recho constitucional (desde una perspectiva 